\title{
CROSS-REACTIVITY OF COVID-19 IGG ASSAY WITH KNOWN IMMUNE-MEDIATED AND INFECTIOUS DISORDERS
}

\author{
Nayab Zehra, Muhammad Dilawar Khan, Hijab Batool, Omar Rasheed Chughtai, Akhtar Sohail Chughtai, Muhammad Usman \\ Chughtai Institute of Pathology, Lahore Pakistan
}

\begin{abstract}
Objective: To assess the cross-reactivity of COVID-19 IgG assay with known immune-mediated and infectious disorders and evaluate for any false-positive reactions to determine the specificity of the serological assay.

Study Design: Cross-sectional analytical study.

Place and Duration of Study: Department of Chemical Pathology, Chughtai Institute of Pathology, Lahore Pakistan, from Sep to Oct 2020.

Methodology: A total of 116 samples were included in the study of both males and females. Diagnosed cases of typhoid fever, viral hepatitis, systemic lupus erythematosus (SLE), syphilis, multiple connective tissue disorders (MCTD), varicella-zoster infection, rabies, toxoplasmosis, epstein-barr virus (EBV) infection, rubella, rheumatoid arthritis, AIDS, cytomegalovirus (CMV) infection and dengue fever were included in the study. Three samples of multiparous women aged more than 40 years were also included in the study. IgG antibody levels were measured against SARS-CoV-2 with a cut-off index of 1.4.

Results: Out of 116, only $3(2 \%)$ samples were reactive for IgG against SARS-CoV-2. The categories showing cross-reactivity were typhoid, hepatitis $\mathrm{C}$, and CMV. All specimens showing cross-reactivity were of females. Assay under consideration showed a specificity of $97.4 \%$.

Conclusion: Cross-reactivity was seen in pre-pandemic cases of infectious diseases with COVID-19 IgG antibody assay. Medical lab professionals must verify the serological assays before use in the clinical laboratory to avoid false-positive results.
\end{abstract}

Keywords: COVID-19, Cross-reactivity, IgG antibody, SARS-CoV-2, Serology.

How to Cite This Article: Zehra N, Khan MD, Batool H, Chughtai OR, Chughtai AS, Usman M. Cross-Reactivity of Covid-19 Igg Assay with Known Immune-Mediated and Infectious Disorders. Pak Armed Forces Med J 2021; 71(6): 2053-2056. Doi: https://doi.org/10.51253/pafmj.v6i6.5685

\footnotetext{
This is an Open Access article distributed under the terms of the Creative Commons Attribution License (https://creativecommons.org/licenses/by-nc/4.0/), which permits unrestricted use, distribution, and reproduction in any medium, provided the original work is properly cited.
}

\section{INTRODUCTION}

A novel corona-virus (SARS-CoV-2) outbreak causing severe acute respiratory syndrome occurred in Wuhan, China, in December 2019. This outbreak spread rapidly all over the world, taking the shape of a pandemic. The outbreak of the corona-virus is not new for mankind. We have been exposed to other members of the corona-virus family, e.g., SARS-CoV-1 in 2003, MERS-CoV- in 2012, and finally SARS-CoV-2 last year (in 2019) ${ }^{1}$. As of 28 March 2021, there have been $126,359,540$ confirmed cases of COVID-19 including 2,769,473 deaths, reported to WHO, worldwide. Since February 18, 2021, at least seven different vaccines across three platforms have been moved out in countries. People at high risk, like front-line workers and old age with more than 60 years of age are the highest priority for vaccination. And since March 25, 2021, a total of $462,824,374$ vaccine doses have been administered. ${ }^{2}$

The symptoms of COVID-19 are not diseasespecific; therefore, the differential diagnosis must be

Correspondence: Dr Nayab Zehra, Clinical Chemistry \& Immunology, Chughtai Institute of Pathology, Lahore-Pakistan

Received: 13 Nov 2020; revision received: 01 Jun 2021; accepted: 09 Jun 2021 established to exclude other life-threatening diseases having major complications. ${ }^{3,4}$ The primary goal of health administration is to control the epidemic of COVID-19 by reducing the infection transmission in the population. This can be achieved by screening the asymptomatic carriers and early detection and containment of infected cases. ${ }^{5}$

The United States food and drug administration (FDA) has authorized many serological tests for SARS$\mathrm{CoV}-2$ under emergencies to screen the population. These serological assays detect antibodies (e.g., IgM, IgG) against SARS-CoV-2 virus or measure a different adaptive immune response (such as, $\mathrm{T}$ cell immune response) to the SARS-CoV-2 virus. However, validation of these serological assays, determination of crossreactivity, and determining diagnostic specificity and sensitivity are of utmost importance before implementing these assays on general population. ${ }^{6,7}$ A new point of care technologies and advanced serological immunoassays have been designed to assess the serological response of the population exposed to the virus. ${ }^{8}$

Determination of antibodies against SARS-CoV-2 can help to assess the percentage of population exposed to the virus, individuals developing immune 
response or having a subclinical infection. Recent studies have revealed that antibodies can remain detectable in a patient's serum for up to 4 weeks. ${ }^{9}$ Seroconversion is achieved after an approximate median of 10 days for IgM and 14 days post-exposure for IgG. This seropositivity can be maximum at about two weeks for IgM and six weeks for IgG. Around seven weeks, IgG attains its peak whereas IgM disappears. IgG antibodies against SARS-CoV-2 in the general population indicate recovery or past exposure to the virus. IgG antibodies against SARS-CoV-2 have a major role during this pandemic. IgG lasts longer and has a strong association with a viral neutralizing activity, which is essential to protect or recover from COVID-19.10

The idea of antibody affinity, avidity, and heterogeneity has been the centre of interest in immunology for the last few decades. It is now considered the key point for understanding molecular interpretations and the concept of cross-reactivity. Subsequently, researchers give great attention to antibody affinity, avidity, variability, and regulation of antibody function and biological alterations of these characteristics. Thus, the antibodies with high affinity and specificity and less heterogeneity can be of prime importance to rule out the false-positive cases, also to distinguish the immune response after vaccination. 7,8

Various health care providing companies around the world have developed advanced serological assays to detect antibodies against SARS CoV-2. Among these assays, chemiluminescence immunoassay has proved to be the highest sensitive and specific. Fully automated enzyme immunoassays using chemiluminescence as a principle have been introduced in Pakistan very recently to determine antibodies in COVID-19 patients. However, the manufacturer's claims regarding crossreactivity about these assays have not been counter checked properly by the local laboratories.

Our study aims to check the cross-reactivity of COVID-19 IgG antibodies with the antibodies of other immune-mediated disorders and infections by using the chemiluminescence technique. This study will help to determine the diagnostic accuracy of the assay and prevent false positives, which produce ambiguity about the immune response.

\section{METHODOLOGY}

This was a cross-sectional analytical study conducted at Chughtai Institute of Pathology, Lahore, after approval from Institutional Review Board under letter no. CIP/IRB/1043. Pre pandemic samples were included in the study collected in November 2019 before the emergence of COVID-19 in Pakistan. A total of 116 samples were included in the study of both males and females after taking informed consent. Data was kept confidential by assigning codes to each patient specimen.

Inclusion Criteria: Diagnosed cases of typhoid fever, Hepatitis A, hepatitis B, hepatitis C, hepatitis D, hepatitis E, systemic lupus erythematosus (SLE), syphilis, multiple connective tissue disorders (MCTD), varicella -zoster, rabies, toxoplasmosis, epsteinbarr virus (EBV) infection, rubella, rheumatoid arthritis, AIDS, cytomegalovirus (CMV) infection and dengue fever were included in the study. Inclusion Criteria: Three samples of multiparous women aged more than 40 years were also included in the study.

Exclusion Criteria: Immuno-compromised patients, patients with malignancy, liver failure, diabetes and organ transplant patients were excluded from the study.

All samples were analysed using Fully Automated Immunoassay Analyzer using chemiluminescence as assay principle. This assay measures IgG antibody levels against SARS-CoV-2 with a specificity of $99.8 \%$ and sensitivity of $100 \%$. A cut-off index (COI) 1.4 was established to see the presence or absence of IgG antibodies reactive against SARS-CoV2. Samples showing values greater than COI were labelled as reactive, and those with values less than the COI were labelled as non-reactive.

Statistical Package for the social sciences (SPSS) version 25 was used for statistical analysis. Simple descriptive analysis was done to find percentagesand frequencies. Chi square test was done and a $p$-value of $\leq 0.05$ was considered as significant. Specificity and negative predictive value were calculated.

\section{RESULTS}

In our study, 116 specimens from 19 different disease categories were tested for potential crossreactivity with SARS-CoV-2 IgG assay. The mean age of participants was $37 \pm 10$ years. Forty-two (42\%) of the participants were male, and $58 \%$ were females. One hundred and $13(97.4 \%)$ specimens were non-reactive for COVID-19 IgG antibody, whereas only $3(2.6 \%)$ were positive. The categories showing cross-reactivity were Typhoid, Hepatitis C, and CMV (Table-I). All the three specimens showing cross-reactivity were of females with ages of 22, 40, and 19 years, respectively. In our study, cross-reactivity was only demonstrated 
in infectious diseases, whereas autoimmune disorders showed no cross-reactivity. Assay under consideration showed a specificity of $97.4 \%$ (Table-II).

\begin{tabular}{|c|c|c|c|}
\hline \multirow[b]{2}{*}{ Disease Category } & \multirow{2}{*}{$\begin{array}{l}\text { No. of } \\
\text { Cases } \\
\text { (n) }\end{array}$} & \multicolumn{2}{|c|}{ COVID-19 IgG } \\
\hline & & Reactive & $\begin{array}{c}\text { Non- } \\
\text { Reactive }\end{array}$ \\
\hline Typhoid Fever & 8 & $1(0.9)$ & $7(6.1)$ \\
\hline Hepatitis A (HAV IgG) & 5 & - & $5(4.2)$ \\
\hline Hepatitis B (Anti HBc) & 4 & - & $4(3.4)$ \\
\hline Hepatitis C (Anti HCV) & 15 & $1(0.9)$ & $14(12.0)$ \\
\hline Hepatitis D (HDV IgG) & 8 & - & $8(6.9)$ \\
\hline Hepatitis E (HEV IgG) & 14 & - & $14(12.1)$ \\
\hline Syphilis & 4 & - & $4(3.4)$ \\
\hline Rabies & 6 & - & $6(5.2)$ \\
\hline $\begin{array}{l}\text { Acquire-immuno- } \\
\text { deficiency-syndrome AIDS } \\
\text { (Anti-HIV) }\end{array}$ & 7 & - & $7(6.1)$ \\
\hline Varicella-zoster Virus (IgG) & 1 & - & $1(0.9)$ \\
\hline Rubella (IgG) & 3 & - & $3(2.6)$ \\
\hline Toxoplasmosis (IgG) & 3 & - & $3(2.6)$ \\
\hline $\begin{array}{l}\text { Cytomegalovirus CMV } \\
\text { (IgG) }\end{array}$ & 10 & $1(0.9)$ & $9(7.8)$ \\
\hline Epstein-bar-virus EBV (IgG) & 2 & - & $2(1.7)$ \\
\hline Dengue Fever (IgG) & 2 & - & $2(1.7)$ \\
\hline $\begin{array}{l}\text { Mixed Connective Tissue } \\
\text { Disease MCTD (ANA) }\end{array}$ & 5 & - & $5(4.2)$ \\
\hline $\begin{array}{l}\text { Systemic-lupus-erythema- } \\
\text { tosus SLE (Anti-ds DNA) }\end{array}$ & 8 & - & $8(6.9)$ \\
\hline Rheumatoid Arthritis & 8 & - & $8(6.9)$ \\
\hline Beta hCG & 3 & - & $3(2.6)$ \\
\hline
\end{tabular}

Table-II: Characteristics of assay under consideration.

\begin{tabular}{l|c|c}
\hline Assay Name & $\begin{array}{c}\text { Negative } \\
\text { predictive value }\end{array}$ & Specificity \\
\hline Chemiluminescence & $100 \%$ & $97.4 \%$ \\
\hline
\end{tabular}

\section{DISCUSSION}

The rapid development of serological assays and diagnostic tools for the early detection of SARS-CoV-2 is important in this ongoing pandemic. Serological assays that target a diversity of viral antigens have assisted in the accurate assessment of the immune status of the population. Data gathered through serological studies can play a vital role in sero-epidemiological estimation in the community and help design vital health care programs. ${ }^{11,12}$ All this is possible if the assay used in the serological studies is sensitive, specific, gives accurate, precise results, and is not potentially cross-reacting. ${ }^{13,14}$ The antibody status of the population provides information about the actual immune status and the ability of the population to contract or resist any infection. ${ }^{15}$ United States Food and Drug Administration (US-FDA) gave emergency authoriza- tion to use serological assays during this pandemic. However, it must be kept in mind that majority of the assays available to use for patient testing still require quality certification and cannot be performed without expert technical supervision. ${ }^{16}$

Our study showed cross-reactivity in only three samples with a specificity of $97.41 \%$, which is very close to the manufacturer's claims (negative agreement 99.63\%). Many studies carried out across the world show similar findings supporting the validity of chemiluminescence assay. A recent study was carried out in Singapore involving 44 Dengue Fever patients and 32 COVID-19 cases. In this study, 2 out of the 44 cases showed cross-reactivity with COVID-19 serological assay, whereas among the COVID-19 patients, no positive dengue serological result was obtained. ${ }^{17} \mathrm{~A}$ case study of an 82-year-old woman who was falsely diagnosed as COVID-19 positive, presented in Greece, later diagnosed as case of Granulomatosis Polyangiitis and recovered after receiving targeted treatment. ${ }^{18}$ An investigation of the SARS-CoV serological assays revealed that $3.5 \%$ of the samples collected from healthy controls showed false seropositivity for IgG, whereas the rate of false positives in patients with autoimmune diseases was $32.8 \%$ in SLE, $10 \%$ in systemic sclerosis, $37.5 \%$ in MCTD and 5\% in rheumatoid arthritis. ${ }^{19}$

COVID-19 is growing at an alarming rate in Pakistan, and government agencies and healthcare professionals may lookout for additional epidemiological solutions to control this pandemic. Determining the accurate immune status of the population can play a vital role in the containment of the infection. ${ }^{20}$ Serological surveys can only be fruitful if done with a valid assay having established sensitivity and specificity. The existence of slight structural similarities between antigens present in other infectious diseases and SARS-CoV-2 must also be considered before validating an assay. Studies reporting cross-reactivity between dengue fever antibodies and SARS-CoV-2 mention structural similarities between the two antigens as the major cause. This cross-reactivity can have considerable implications in areas where many infections and immune-mediated diseases prevail at the same time.

In developing countries of the world like Pakistan, many infectious diseases still exist in the background of COVID-19. Under these circumstances, the obvious question which arises is whether the antibodies present in the population as a result of exposure to already prevalent diseases will cross-react with COVID-19 serological tests. If this is true, sero-surveys 
have to be carried out with adequate precautions and care in the regions where various infections co-exist. In addition, interpretation of the results has to be carried out by authorized personnel, taking into account supporting information from the patient to avoid inaccurate conclusions.

\section{ACKNOWLEDGMENT}

We would like to thank the staff of the Department of Chemical pathology who helped us in carrying out this research

\section{CONCLUSION}

Cross-reactivity was observed in the pre-pandemic samples before the emergence of COVID-19 in Pakistan, and the assay showed acceptable diagnostic specificity. Medical lab professionals must validate the serological assays before use as false-positive results due to cross-reactivity can lead to the wrong estimation of the population's immune status.

Conflict of Interest: None.

Funding Source: Chughtai Lab Lahore work.

\section{Authors' Contribution}

NZ: Write up, Literature review, sample collection and analysis, MDK: Supervision and review, HB: Data Analysis, ORC: Proof reading, literature review, ASC: Approval, MU: Sample collection and analysis.

\section{REFERENCES}

1. Huang C, Wang Y, Li X, Ren L, Zhao J, Hu Y, et al. Clinical features of patients infected with 2019 novel coronavirus in Wuhan, China. Lancet 2020; 395(10223): 497-506.

2. WHO Coronavirus (COVID-19) Dashboard. COVID19. WHO. Int. 2021. [Internet] Available at: https://covid19.who.int/ [Accessedon March 28, 2021].

3. Pinotti F, Wikramaratna P, Obolski U, Paton R, Damineli D, Alcantara L, et al. Potential impact of individual exposure histories to endemic human coronaviruses on age-dependent severity of COVID-19. BMC Med 2021; 19(1): 19-22.

4. Tzouvelekis A, Karampitsakos T, Krompa A, Markozannes E, Bouros D. False positive COVID-19 antibody test in a case of granulomatosis with polyangiitis. Front Med (Lausanne) 2020; 7(2): 399.

5. Delamater PL, Street EJ, Leslie TF, Yang YT, Jacobsen KH. Complexity of the basic reproduction number (R0). Emerg Infect Dis 2019; 25(1): 1-5.
6. Alba M, Jennette J, Falk R. Pathogenesis of ANCA-associated pulmonary vasculitis. Semin Respir Crit Care Med 2018; 39(4): 413-424.

7. Arslan B, Timucin A. Immunotherapy approaches on innate immunity for SARS-Cov-2. Acta Virol 2020; 64(4): 389-395.

8. Younes N, Al-Sadeq DW, AL-Jighefee H, Younes S, Al-Jamal O, Daas HI, et al. Challenges in Laboratory Diagnosis of the Novel Coronavirus SARS-CoV-2. Viruses 2020; 12(6): 582.

9. Bao L, Deng W, Gao H. Reinfection could not occur in SARSCoV-2 infected rhesus macaques. Bio Rxiv 2020; 3(13): 990226.

10. Rongqing Z, Li M, Song H, Chen J, Ren W, Feng Y, et al.Early Detection of Severe Acute Respiratory Syndrome Coronavirus 2 Antibodies as a Serologic Marker of Infection in Patients With Coronavirus Disease 2019. Clin Infect Dis 2020; 71(16): 2066-2072.

11. Shen C, Wang Z, Zhao F. Treatment of 5 Critically Ill Patients with COVID-19 With Convalescent Plasma. JAMA 2020; 323(16): 1582-1589.

12. Lee C, Lin R, Renia L, Ng L. Serological Approaches for COVID19: Epidemiologic Perspective on Surveillance and Control. Front Immunol 2020; 11(1): 879.

13. Li X, Xu S, Yu M, Wang K, Tao Y, Zhou Y, et al. Risk factors for severity and mortality in adult COVID-19 inpatients in Wuhan. J Allergy Clin Immunol 2020; 146(1): 110-118.

14. Zuo Y, Zuo M, Yalavarthi S, Gockman K, Madison J, Shi H, et al. Neutrophil extracellular traps and thrombosis in COVID-19. J ThrombThrombol 2020; 51(2): 446-453.

15. Jacofsky D, Jacofsky E, Jacofsky M. Understanding Antibody Testing for COVID-19. J Arthroplast 2020; 35(7): S74-S81.

16. Binnicker M. Emergence of a novel coronavirus disease (COVID19) and the importance of diagnostic testing: why partnership between clinical laboratories, public health agencies, and industry is essential to control the outbreak. Clin Chem 2020; 66(5): 664-666.

17. Spinicci M, Bartoloni A, Mantella A, Zammarchi L, Rossolini G. Low risk of serological cross-reactivity between dengue and COVID-19. Mem Inst Oswaldo Cruz 2020; 115(1): e200225.

18. Tzouvelekis A, Karampitsakos T, Krompa A, Markozannes E, Bouros D. False positive COVID-19 antibody test in a case of granulomatosis with polyangiitis. Front Med (Lausanne) 2020; 7(2): 399.

19. Vojdani A, Kharrazian D. Potential antigenic cross-reactivity between SARS-CoV-2 and human tissue with a possible link to an increase in autoimmune diseases. Clin Immunol 2020; 217(1): 108480.

20. Yong S, Anderson D, Wei W, Pang J, Chia W, Tan C, et al. Connecting clusters of COVID-19: an epidemiological and serological investigation. Lancet Infect Dis 2020; 20(7): 809-815. 